\title{
CAN CAPACITIES RESCUE Us From CETERIS PARIBUS LAWS?
}

\begin{abstract}
Many philosophers of science think that most laws of nature (even those of fundamental physics) are so called ceteris paribus laws, i.e., roughly speaking, laws with exceptions. Yet, the ceteris paribus clause of these laws is problematic. Amongst the more infamous difficulties is the danger that 'For all $\mathrm{x}$ : Fx $\supset \mathrm{Gx}$, ceteris paribus' may state no more than a tautology: 'For all $\mathrm{x}$ : Fx $\supset$ Gx, unless not'.

One of the major attempts to avoid this problem (and others concerning ceteris paribus laws) is to claim that the subject matter of laws are ascriptions of dispositions, powers, capacities etc., and not the regular behaviour we find in nature. That we do not know whether the cetera are paria in a specific situation does not matter to the dispositionalist because the objects have the disposition regardless of the circumstances. The defence of the latter claim is that dispositions can be instantiated without being manifested. Hence, the laws that ascribe dispositions are strict and it looks as if they do not face the above mentioned problems of ceteris paribus laws.

In this essay I attempt to show that these assumptions are wrong. I hope to illustrate that not only does the ceteris paribus clause reoccur inside the dispositions, moreover, there are laws - laws about non-fundamental entities with instable dispositions - which bear a ceteris paribus clause that cannot be hidden in a disposition.
\end{abstract}

\section{All PREVAILING CETERIS PARIBUS LAWS}

Many philosophers of science think that all, most, or many laws of nature are so called ceteris paribus laws. Take the following statements for examples:

\footnotetext{
"All laws are ceteris paribus laws. (in Fn.) I even intend to include most so-called fundamental laws of physics." (Cartwright 1995: 155)

"Whatever the law says must happen, hold or obtain, everything else being equal." (Harré 1993: 79)

"The validity of most laws - even of a fundamental physical kind - is compatible with the existence of exceptional situations." (Kistler 2003: 192)
}

The notion 'ceteris paribus' - literally 'all else being equal' - is usually read in a broad sense; namely, that a ceteris paribus law is a law which sometimes has exceptions. I adopt this broad reading. It should be mentioned, however, that it would be better to speak more generally of proviso laws if we have this broad sense in mind and of ceteris paribus only if we really mean that something, circumstances for example, have to be equal to a certain standard. In any case, and disregarding these verbal issues, my focus will be on the underlying unifying feature of the whole variety of proviso laws: in some cases the proviso law does not hold good; ${ }^{1}$ it faces prima facie a falsification while nonetheless being a law, i.e., the prima facie falsification is just an exception.

\section{The Problems with the Ceteris paribus Clause}

Although many think that there are ceteris paribus laws - not only in the proviso-ridden social sciences but even all the way down to fundamental physics - the ceteris paribus clause in law statements is problematic. Three infamous difficulties are well known.

(1) 'For all x: Fx $\supset$ Gx, ceteris paribus', is in danger of being tautologous or

\footnotetext{
${ }^{1}$ Better, the core of the proviso law does not hold good; where I define: the core of ' $\forall \mathrm{x}$ (Fx $\supset$ Gx), ceteris paribus' is $\forall \mathrm{x}(\mathrm{Fx} \supset \mathrm{Gx})$.
} 
incomplete: tautologous if we specify or define the ceteris paribus clause by saying circularly 'For all $\mathrm{x}: \mathrm{Fx} \supset \mathrm{Gx}$, except in those cases where Fs are not Gs'; incomplete if the ceteris paribus clause is thought to be cashed out by demanding (in the antecedent of the law) that possible interferences A, B, C, etc. do not occur. The problem with this variant is that we most certainly have to leave a gap in our statement 'For all $\mathrm{x}$ : Fx and ?x $\supset$ Gx' because either we do not know all the interferers, or there are endlessly many interferers, or the class of exceptions is too heterogeneous. In the latter case it is not certain whether the exclusion clause can be formulated in the terms of the science to which the law belongs, that is, the interfering phenomena could possibly not belong to the scope of the science of the law under concern. In "Birds can fly, unless they are struck by a lightning", the weather conditions are not a biological phenomenon.

Tautologous statements are empirically not very useful, since they are empirically vacuous. Incomplete statements, on the other hand, fail to express any well-determinate content and, hence, to pick out a law of nature.

(2) Apart from these semantic problems of ceteris paribus law statements, proviso laws face other, epistemic, difficulties: proviso laws can neither be confirmed in any situation, since they do not hold good in any situation, nor can they be refuted easily.

The ceteris paribus clause could be misused as an immunisation strategy: we could claim that whenever the law does not hold the cetera weren't paria. A bad result for the sciences if we are keen on demarcation: a non-falsifiable empirical science is in danger of resembling a pseudo-science like astrology.

(3) Finally, ceteris paribus laws do not support counterfactuals, and are of little help in predictions, since we do not know whether in those counterfactual and/or future circumstances the cetera are paria.

Whilst I am sure there are many more problems with provisos, (1) vacuity because of being either tautologous, or incomplete, (2) being uncomfirmable and not falsifiable, and (3) being unable to support counterfactuals or predictions are certainly amongst the most famous ones.

Note finally that the difficulties I have mentioned are not tied to a specific account of lawhood. They arise for anti-Humean theories based on necessary connections between universals and for neo-Humean regularity accounts alike. As we shall see now ( 33$)$ it is the dispositionalist's main claim that the latter theories especially, i.e., regularity theories, are threatened by those problems.

\section{THE DISPOSITIONALIST'S INTEREST IN CETERIS PARIBUS LAWS}

The question of my paper is 'Can Capacities Rescue Us From Ceteris paribus Laws?' It is noteworthy that this is usually not the question proponents of dispositions like Cartwright, Kistler, Hüttemann, Lipton, Bartels etc. emphasise. ${ }^{2}$ That is, the dispositionalists' motivation for claiming that the subject matter of all laws are dispositions is not primarily that dispositions solve all the problems the ceteris paribus clause poses.

A proper theory of ceteris paribus laws is actually only a marginal step in their enterprise. Their main goal is to show that the problems of proviso laws are only problems if we subscribe to a regularity theory of lawhood. ${ }^{3}$ Because of this, ceteris paribus laws are, for the dispositionalist, a welcome battleground against Humeans where best hope of winning seems to be with the one who has got the powers and capacities.

\footnotetext{
${ }^{2}$ See (Bartels 2000), Cartwright in several publications, e.g., (Cartwright 1989), (Cartwright 1992), (Cartwright 1999), (Cartwright 2002), (Hüttemann 1998), (Lipton 1999), (Kistler 2003).

${ }^{3}$ As I discovered later this has already been underlined by Earman, Roberts, and Smith in their article "“Ceteris paribus" Lost' (Earman, Roberts, and Smith 2002).
} 
The argument is roughly this:

(1) There are ceteris paribus laws all the way down the sciences.

(2) We cannot make sense of ceteris paribus laws if we adopt a regularity view of laws.

(3) But they do make sense if we adopt dispositionalism.

Hence, dispositionalism.

The offended Humean anti-dispositionalist usually responds to this argument by attacking (1), i.e., by denying the existence of ceteris paribus laws. It is the Humean's creed that the fundamental laws of physics are strict. Adding to this belief the reductionist claim that every science is reducible to physics they think they can avoid dispositionalism.

I myself do not intend to defend the Humeans, that is, I do not intend to argue against dispositions, powers, capacities, natures etc. I try to remain neutral on this matter. I will nevertheless try to cast doubt on dispositionalism (which I understand from this point on as both the thesis that dispositions, capacities, powers, tendencies, etc. exist on top or instead of laws and that they can rescue us from ceteris paribus laws). My plan of attack focuses on (3), not (1). But before I present my central arguments in $\S 6$ and $\S 8$ let us (in $\S 4$ ) see how the dispositionalist argues for (1), (2) and (3).

\section{The Dispositionalist's IdEA ABOUT CETERIS PARIBUS LAWS}

Why do dispositionalists believe that they can avoid the problems ceteris paribus laws pose? As the quotations from above reveal, the dispositionalist's presupposition is that all, most, or many laws are ceteris paribus laws. Take for example the prototype of a law, Newton's law of gravitation. It says that masses $m$ attract other masses $M$ at distance $r$ with the gravitational force $\mathrm{F}_{\mathrm{G}}=\mathrm{GmM} / \mathrm{r}^{2}$. Let's consider the special case of the earth and an arbitrary massive object near its surface, an overhead transparency for example. If I let it drop, will it fall according to the equation for the motion derived directly from the law of gravitation? It won't. There can be all sorts of interferences: air resistance, the blowing of the overhead projector's fan, electromagnetic forces due to electrostatic charge of the plastic, etc. So, even the prototype of lawhood - the law of gravitation - is a ceteris paribus law and we have a good reason for (1), i.e., that there are ceteris paribus laws all the way down the sciences. I quote Cartwright:

The force of size $G M m / r^{2}$ does not appear to be there; it is not what standard measurements generally reveal; and the effects we are entitled to expect - principally an acceleration in a system of mass $m$ a distance $r$ away of size $G M / r^{2}$ - are not there either. (Cartwright 2002: 428)

Real objects nearly never display the laws which are supposed to hold for them. If taken as statements about regularities laws are either all false or they are ceteris paribus laws because there are hardly ever regularities. But if the law of gravitation is not a regularity what is it then and what are all the other putative laws?

The dispositionalists' solution is to claim that the law of gravitation and others are not about objects' behaviour but about their disposition to behave. The objects do in fact have these dispositions, but they might not be displayed or only partially displayed in real situations.

The laws we use talk not about what bodies do, but about the powers they possess. (Cartwright 1983: 61)

The idea is that the properties linked by a law are dispositional rather than manifest. (Kistler 2003: 192)

To say that laws describe how physical systems would behave in specified situations is to say that laws ascribe dispositions to physical systems. (Hüttemann 1998: 129)

We don't know when all things are equal, but the whole point of the dispositional view is in 
a sense that we do not need to know, since the disposition is present regardless. (Lipton 1999: 166)

The basis of those thoughts is that dispositions can be present without their manifestation being realised. To put it another way, dispositions seem to be able to play the double role we need for ceteris paribus laws, namely permanence and absence at the very same time. Permanence because even if the circumstances are not fortunate and the lawlike behaviour is not displayed we think of laws as remaining somehow in good order. Absence because it seems that the law has - although still existent—little or no impact or manifestation if things are not equal.

So far so good. Laws are about which kinds of objects have which dispositions and not about what objects do. That is great news because we can drop the ceteris paribus clause of the laws. Our newly interpreted laws are strict. Massive objects have the power to attract other masses, negative charges have the power to repel other negative charges, etc., regardless of the actual circumstances or actual behaviour. Therefore we get rid of all the problems ceteris paribus laws pose since our laws are strict now. Or are they?

\section{Does DispositionalisM SOlVE THE Difficulties OF CETERIS PARIBUS}

\section{LAWS?}

I have divided the dispositionalists' overall argument into three parts: (1) There are ceteris paribus laws all the way down. (2) We cannot make sense of ceteris paribus laws if we adopt a regularity view of laws. (3) But they do make sense if we adopt dispositionalism. I have just presented the dispositionalists' arguments for (3). To support the first claim (1) I have quoted the law of gravitation as an example. Claim (2) is made plausible by the problems I have listed earlier for ceteris paribus laws and by mentioning that those problems affect every other theory of lawhood but dispositionalism and, hence, a fortiori regularity theories. So, can we conclude that dispositionalism is the way to solve, or better, to avoid the problems of ceteris paribus laws?

I think that even if we grant that dispositionalism (as opposed to Humeanism) is the correct metaphysical stance on laws of nature it is still an illusion that we have escaped the ceteris paribus problems. Taking quotes from the works of the most prominent dispositionalist, namely, Nancy Cartwright, I will present two major difficulties: ${ }^{4}$

First: dispositionalists have so far only gestured at, but never spelled out in detail, what their new law statements-law statements involving dispositional concepts-look like. It will prove more difficult than it might seem to come up with a precise version of, say, Coulomb's law which will satisfy the dispositionalist. Moreover, while arriving at a dispositionalist formulation it becomes clear that the ceteris paribus clause sneaks back in again. (see §6)

Second: the difference between an object whose disposition's manifestation is masked or counteracted against and one whose disposition is lost (because the basis is lost) has not been properly distinguished. The latter case leads to a sort of ceteris paribus clause which cannot be accommodated by dispositionalism easily (see $\S 8$ ).

\section{How THE CETERIS PARIBUS Clause RE-ENTERS THE STAGE}

First and foremost, note that the alleged capacity concepts of scientific theories have to have

\footnotetext{
${ }^{4}$ I will take Coulomb's law as an example for my enquiry. Any of my arguments should be applicable to at least all the other force laws.
} 
an internal mathematical functional structure just like laws do. ${ }^{5}$ Charges $q$ do not simply have the capacity to attract (repel) other charges $Q$ but, roughly, to attract (repel) other charges $Q$ in distance $r$ with force $F_{C}=q Q /\left(4 \pi \varepsilon_{0} r^{2}\right)$. Dispositionalists agree that otherwise dispositions cannot take over the former laws' job. Hence, Cartwright writes:

Coulomb's capacity differs from everyday ones [in] that it has an exact functional form and precise strength, which are recorded in its own special law. (Cartwright 1999: 54) ${ }^{6}$

With this important insight I will try to formulate the new kind of law in a trial and error manner. Eventually only the last, the third, attempt will prove to be a good candidate. I start with my first suggestion: charges, so we are told, have Coulomb's capacity $\mathrm{C}$ to attract (repel) other charges: "Coulomb's law tells not what force charged particles experience but rather what it is in their nature, qua charged, to experience." (Cartwright 1992: 48). Hence, the following formulation should express the dispositionalist's law, or so it seems,:

(1) It is a strict law that for any two objects $\mathrm{x}$ and $\mathrm{y}$ if they have charge $\mathrm{q}$ and $\mathrm{Q}$ respectively and are in distance $r$ to each other then $\mathrm{x}$ has the capacity $\mathrm{C}$ to exert the force $F_{C}=q Q /\left(4 \pi \varepsilon_{0} r^{2}\right)$ on $y$ (and v.v. for $y$, i.e., $y$ has the capacity to exert the force $F_{C}=$ $\mathrm{qQ} /\left(4 \pi \varepsilon_{0} \mathrm{r}^{2}\right)$ on $\left.\mathrm{x}\right)$.

This, however, cannot be right. In reading (1) the capacity $\mathrm{C}$ is the capacity to exert force $F_{C}$, i.e., an exerted force $\mathrm{F}_{\mathrm{C}}$ would be the capacity's manifestation. Yet, the immediate question is: when is this capacity manifested, i.e., what is the trigger for that capacity and/or under which circumstances does it manifest itself? $\mathrm{C}$ is the capacity to exert force $\mathrm{F}_{\mathrm{c}}$ if what? ${ }^{7}$

That this question needs an answer stems from old empiricist concerns. For the capacity to be a respectable entity we must be able to test it. In fact, the dispositionalists insist themselves that their capacities are empirically testable, even measurable. "Causal capacities can be measured as surely - or unsurely - as anything else that sciences deals with. Sometimes we measure capacities in a physics laboratory." (Cartwright 1989: 7) Yet, it is the demand for the possibility of a test or measurement operation which forces us to spell out a condition under which the respective capacity will manifest itself. For how are we to measure the capacity if we do not know how to trigger its manifestation? More forcefully, if there are capacities which are just the capacities to do xyz without there being a specified trigger condition then what is to prevent us from supposing that everything has those trigger-less capacities (no test could ultimately prove that they do not).

So what is the trigger in our concrete case? If we answer that it is the location of the two charges in distance $r$ we get an undesirable result because the trigger condition would appear twice: once as antecedent of the law and once as antecedent of the capacity.

(1*) It is a strict law that for any two objects $\mathrm{x}$ and $\mathrm{y}$ if they have charge $\mathrm{q}$ and $\mathrm{Q}$ respectively and are in distance $r$ to each other then $\mathrm{x}$ has the following capacity: to exert the force $\mathrm{F}_{\mathrm{C}}=\mathrm{qQ} /\left(4 \pi \varepsilon_{0} \mathrm{r}^{2}\right)$ on $\mathrm{y}$ if it has charge $q$ and is in distance $r$ to $y$ with charge $Q$ (and v.v. for $\mathrm{y}$ ).

This redundant claim cannot be the new law formulation the dispositionalist is after. Apart from the redundancy which is already a reason not to accept the statement - it would also make the disposition's manifestation a sure thing because the disposition's antecedent is met whenever the law's antecedent is fulfilled. In other words, the disposition manifests whenever it is instantiated and this means we can get rid of the disposition entirely and just write:

\footnotetext{
${ }^{5}$ If this does not hold for all of them my critique might only count for those for which does (although I believe that my critique could then be extended with only a few alterations).

${ }^{6}$ A puzzle aside the main line of argument is, by the way, the ontological issue whether there is then just one capacity or one for each masses-distance-force triple.

${ }^{7}$ Compare: fragility - the capacity to break easily if struck; solubility - the capacity to solve if immersed in water.
} 
$\left(1^{* *}\right)$ It is a strict law that for any two objects $\mathrm{x}$ and $\mathrm{y}$ if they have charge $\mathrm{q}$ and $\mathrm{Q}$ respectively and are in distance $r$ to each other then $x$ exerts the force $F_{C}=q Q /\left(4 \pi \varepsilon_{0} r^{2}\right)$ on $y$ (and v.v. for y).

That is, we would be back to the law with which we started. The obvious step to take is to delete some trigger conditions from the antecedent of the law. Hence my second suggestion:

(2) It is a strict law that for any two objects $x$ and $y$ if they have the charges $q$ and $Q$ respectively then $x$ has the following capacity: to exert the force $F_{C}=q Q /\left(4 \pi \varepsilon_{0} r^{2}\right)$ on object $\mathrm{y}$ if $\mathrm{x}$ is in distance $\mathrm{r}$ to $\mathrm{y}$ (and v.v. for $\mathrm{y}$ ).

I have reduced the antecedent condition of the law to 'if charges' (as opposed to the first suggestion: if charges in distance $r$ then capacity), i.e., now having charge is sufficient to have the capacity. ${ }^{8}$

Suggestion (2) has, however, still a consequence which the dispositionalist cannot welcome. In order to see that, let me repeat the main advantage dispositionalists find in capacities: capacities fulfil a double role, that is, they can be instantiated without being manifested. As we will see now this claim needs qualification, for what cannot be meant by this claim is the triviality that although the capacity can be instantiated its antecedent condition might not be met so that it does not manifest. Compare solubility: sugar is soluble, but sugar does not solve if it is not put in water. Translated into Coulomb's capacity a single charge has Coulomb's capacity but trivially it does not manifest if there is no second charge around at distance $r$.

The crucial feature the dispositionalists are after has to be something deeper. They have to stipulate that a capacity can fail to manifest even though the trigger is pulled, i.e., even though the antecedent of the disposition is met. Here, that a charge $q$ fails to exert the force $\mathrm{F}_{\mathrm{C}}$ even though another charge $\mathrm{Q}$ is present in distance $r .{ }^{9}$ Indeed, this is what Cartwright says:

\begin{abstract}
Consider Coulomb's law of electrostatic attraction and repulsion. Coulomb's law says that the force between two objects of charge $\mathrm{q}_{1}$ and $\mathrm{q}_{2}$ is equal to $\mathrm{q}_{1} \mathrm{q}_{2} / \mathrm{r}^{2}$ [sic!]. Yet, this is not the force the bodies experience; they are also subject to the law of gravity. [...] Coulomb's is not the force that actually occurs; rather, it is a hypothetical power hidden away in the actual force. (Cartwright 1992: 48).
\end{abstract}

However, this demand - that the capacity fails to manifest although its antecedent is met - is not fulfilled by our definition (2) which, so far, stipulates that if the trigger is pulled the capacity must manifest.

Yet, the changes we have to make to (2) in order to meet the new requirement are devastating: the capacity has, internally, to bear a proviso: an object $\mathrm{x}$ with charge $\mathrm{q}$ exerts the force $\mathrm{F}_{\mathrm{C}}=$ $\mathrm{qQ} /\left(4 \pi \varepsilon_{0} \mathrm{r}^{2}\right)$ on object $\mathrm{y}$ if $\mathrm{x}$ is in distance $\mathrm{r}$ to $\mathrm{y}$ and $\mathrm{y}$ has charge $\mathrm{Q}$, ceteris paribus(!)-where ceteris paribus means (amongst other things) that no masses should be around. The amended version of (2) then reads:

(2*) It is a strict law that for any two objects $\mathrm{x}$ and $\mathrm{y}$ if they have the charges $\mathrm{q}$ and $\mathrm{Q}$ respectively then $\mathrm{x}$ has the capacity $\mathrm{C}$ which is the capacity to exert the force $\mathrm{F}_{\mathrm{C}}=$ $\mathrm{qQ} /\left(4 \pi \varepsilon_{0} \mathrm{r}^{2}\right)$ on object $\mathrm{y}$ if $\mathrm{x}$ is in distance $\mathrm{r}$ to $\mathrm{y}$, ceteris paribus (and v.v. for $\mathrm{y}$ ).

Note that the whole phrase after 'which is the capacity...' is the characterisation of the capacity $\mathrm{C}$, i.e., the ceteris paribus clause is contained within that characterisation and does not contradict the strictness of the overall law which states that charges always have that

\footnotetext{
${ }^{8}$ Actually, one has to give some thoughts to whether we should formulate the dispositionalists' claim for a single object $\mathrm{x}$ or as done here for two objects $\mathrm{x}$ and $\mathrm{y}$. However, a reformulation just for $\mathrm{x}$ would not affect my arguments.

9 A point which I cannot discuss here is that dispositionalists have to go even one step further: they have to stipulate that once the antecedent conditions are met the disposition is trying, urging, pressing, pushing to manifest but does not succeed.
} 
capacity.

In any case, we are back to the ceteris paribus clause and all the problems of ceteris paribus laws as mentioned in $\$ 2$ are simply shifted one level down. The capacity the dispositionalists have invented turns out to be a veil covering the ceteris paribus clause.

But maybe I have completely misunderstood dispositionalism and the whole reconstruction $\left(2^{*}\right)$ is wrong. Another possible interpretation should be discussed:

(Proto 3) It is a strict law that for any two objects $\mathrm{x}$ and $\mathrm{y}$ if they have charge $\mathrm{q}$ and $\mathrm{Q}$ respectively then $x$ has the Coulomb force capacity $F_{C}$ (and v.v. for $y$ ), i.e., the capacity is identified with the force; the force itself $i$ s the capacity sought after.

The force (seen as a capacity) is there in any case: 'if charge then force' is a strict law. It is, however, the force's manifestation (that is its effect) which might not occur. So far this sounds like a promising claim. Yet, what is a force capacity's trigger and what is its manifestation? The force capacity is the capacity to do what and when?

I take it that it is rather uncontroversial to identify the manifestation with an acceleration - here the acceleration $\mathrm{a}=\mathrm{qQ} /\left(4 \pi \varepsilon_{0} \mathrm{r}^{2}\right) / \mathrm{m}$ (with $\mathrm{m}$ being the mass of $\mathrm{x}$; mutatis mutandis for $\mathrm{y}) .{ }^{10}$ But what are the antecedent conditions for this force disposition? For a start, I take just the presence of the two charges in distance $r$ as the trigger. Hence, the Coulomb force capacity has the following overall structure: two objects $\mathrm{x}$ and $\mathrm{y}$ each have the force capacity $\mathrm{F}_{\mathrm{C}} \leftrightarrow$ if $\mathrm{x}$ is in distance $\mathrm{r}$ to $\mathrm{y}$ then $\mathrm{x}$ is accelerated towards $\mathrm{y}$ with $\mathrm{a}=\mathrm{qQ} /\left(4 \pi \varepsilon_{0} \mathrm{r}^{2}\right) / \mathrm{m}$ ( $\mathrm{m}$ being the mass of $\left.\mathrm{x}\right)^{11}$ (mutatis mutandis for $\left.\mathrm{y}\right)^{12}$. So the overall law statement of the dispositionalist reads as follows:

(3) It is a strict law that for any two objects $x$ and $y$ if they have charge $q$ and $Q$ respectively then $x$ has the Coulomb force capacity $F_{C}$ which is the following capacity: to accelerate towards $\mathrm{y}$ with $\mathrm{a}=\mathrm{qQ} /\left(4 \pi \varepsilon_{0} \mathrm{r}^{2}\right) / \mathrm{m}$ if $\mathrm{x}$ is in distance $\mathrm{r}$ to $\mathrm{y}$ (and mutatis mutandis for y).

Unfortunately, this definition is at odds in two respects with Cartwright's quote from above. Reconsider: "Yet, this is not the force the bodies experience; they are also subject to the law of gravity." (Cartwright 1992: 48). So, firstly, where Cartwright says that Coulomb's force is not there in certain cases (3) claims that Coulomb's force is always there. What the bodies might indeed not experience (according to (3)) is the Coulomb force capacity's manifestation, i.e., a certain acceleration. If, then, we take (3) for granted we have to change Cartwright's claim to: "Yet, this is not the acceleration(!) the bodies experience; they are also subject to the law of gravity". The second respect in which (3) does not match up with Cartwright's quote is the same for which (2) was imperfect and had to be changed to $\left(2^{*}\right)$ : we have not taken care of the possibility that the manifestation might well not occur although the antecedent condition of the force capacity is met. This is, for example, the case when, to take Cartwright's example, also masses, and not only charges, are around. Taking care of this fact we arrive, similar to $(2 *)$, at $(3 *)$ :

(3*) It is a strict law that for any two objects $x$ and $y$ if they have charge $q$ and $Q$ respectively then $\mathrm{x}$ has the Coulomb force capacity $\mathrm{F}_{\mathrm{C}}$ which is the following capacity: to accelerate towards $\mathrm{y}$ with $\mathrm{a}=\mathrm{qQ} /\left(4 \pi \varepsilon_{0} \mathrm{r}^{2}\right) / \mathrm{m}$ if $\mathrm{x}$ is in distance $\mathrm{r}$ to $\mathrm{y}$, ceteris paribus (and

\footnotetext{
${ }^{10}$ However, this claim will be challenged below.

${ }^{11}$ Note that X's and y's being charged does not appear anymore in this force capacity's antecedent. This is acceptable because objects $\mathrm{x}$ and $\mathrm{y}$ have this force capacity if they are charged. It's the law (if charge then forcecapacity) which takes care of the fact that the particles are charged. (One might even go one step further and claim that the law is a bi-conditional: charge if and only if Coulomb-force-capacity. But I do not have the space to discuss this, maybe essentialist, possibility here.)

${ }^{12} \mathrm{y}$ is accelerated towards $\mathrm{y}$ with $\mathrm{a}=\mathrm{qQ} /\left(4 \pi \varepsilon_{0} \mathrm{r}^{2}\right) / \mathrm{M} ; \mathrm{M}$ being the mass of $\mathrm{y}$.
} 
mutatis mutandis for y). ${ }^{13}$

A brief excursus: in principle, there is another logical possibility to accommodate the needed ceteris paribus caveat in version (3). We could claim that the antecedent of the law (not the capacity) has to bear the ceteris paribus clause which would amount to the claim that not in any circumstances would a charged object $x$ have Coulomb's force capacity $F_{C}$ : it is a law (not a strict law!) that for any two objects $\mathrm{x}$ and $\mathrm{y}$ if they have charge $\mathrm{q}$ and $\mathrm{Q}$ respectively then $\mathrm{x}$ has, ceteris paribus, Coulomb's force capacity $\mathrm{F}_{\mathrm{C}}$. This, however, would bring us straight back to the original ceteris paribus law itself (or a very close relative) and it was the dispositionalists' aim to avoid that.

In the light of the last remark it could seem to be a matter of choice where the ceteris paribus proviso appears: if you prefer it inside a capacity choose dispositionalism, if you prefer it at the law-level choose orthodox theories of lawhood. That things turn out to be even more complex will be discussed in $\S 8$. For now let's suppose we have discarded the version with the ceteris paribus clause at the law level.

Back to version $\left(3^{*}\right)$, I have to ask whether it is legitimate to exchange forces for accelerations in Cartwright's statement (as done above) and, more importantly, how authentic it is to introduce the ceteris paribus clause into the capacity. A later claim of Cartwright's can serve as justification for the latter: "It is in the nature of a force to produce an acceleration of the requisite size. That means that ceteris paribus, it will produce that acceleration." (Cartwright 1999: 28; my emphasis) This fairly recent quote seems to be in full accordance with my analysis $\left(3^{*}\right)$.

Anyway, the attempt to find an alternative interpretation to $\left(2^{*}\right)$ in order to avoid a ceteris paribus clause, has been frustrated. Whichever way turns out to be the right one, $\left(2^{*}\right)$ or $\left(3^{*}\right)$, to spell out dispositionalism in detail-it unavoidably contains a ceteris paribus clause. Hence, my primary goal here (§6), to show that it is doubtful whether dispositionalism can rescue us from ceteris paribus clauses in laws has been achieved. ${ }^{14}$

However, I must spend some more time on deciding whether $\left(2^{*}\right)$ or $\left(3^{*}\right)$ is the correct reading of dispositionalism. Recall that $\left(2^{*}\right)$ defines a capacity $\mathrm{C}$ which is the capacity to exert a force when circumstances are right, where $\left(3^{*}\right)$ says that the capacity $i$ s the force $\mathrm{F}_{\mathrm{C}}$ which, when the circumstances are right, will have an acceleration as its effect. Both $\mathrm{C}$ and $\mathrm{F}_{\mathrm{C}}$ are supposed to be linked strictly to charges, i.e., it is either a strict law that charges have $\mathrm{C}$ or it is a strict law that charges have $\mathrm{F}_{\mathrm{C}}$ depending on which version, $\left(2^{*}\right)$ or $\left(3^{*}\right)$, turns out to be the right interpretation of dispositionalism.

A lot counts for $\left(2^{*}\right)$ being the right interpretation. $\left(2^{*}\right)$ is suggested by Cartwright's statement from 1992:

Yet, this is not the force the bodies experience; they are also subject to the law of gravity. $[\ldots]$ Coulomb's is not the force that actually occurs; [...] Coulomb's law tells not what force charged particles experience but rather what it is in their nature, qua charged, to experience. (Cartwright 1992: 48).

And also by a statement from 1999:

To say that it is in their nature to experience a force of $\mathrm{q}_{1} \mathrm{q}_{2} / 4 \pi \varepsilon_{0} \mathrm{r}^{2}$ is to say at least that they

\footnotetext{
${ }^{13}$ And again, the ceteris paribus clause is inside the force capacity. That a charge has that capacity remains a strict law.

${ }^{14}$ With a different argument Peter Lipton comes to a similar conclusion: "[The] problem for the occurrent view of cp laws [i.e., the regularity view dispositionalists fight against; MAS] is that we cannot give cp laws determinate content because we cannot specify the antecedent of the law; the problem for the dispositional view is that we cannot give the dispositional attribution determinate content because we cannot specify the antecedent of the corresponding conditional that would give the dispositional term its meaning. So we have made no advance." (Lipton 1999: 167)
} 
would experience this force if only the right conditions occur for the power to exercise itself 'on its own'. (Cartwright 1999: 82) (15 $^{15}$

Also, other authors seem to have interpreted dispositionalism in the way of (2*). Summarising the essence of Cartwright's theory, Earman and Roberts say:

\begin{abstract}
They [laws] are attributions of capacities and tendencies to various kinds of systems; in a nutshell, 'cp: $(\mathrm{x})(\mathrm{Fx} \rightarrow \mathrm{Gx})$ ' is true just in case all Fs have a capacity or tendency to be $\mathrm{G}$, so that they will be $\mathrm{G}$ in (the rare) cases where there are no other capacities or tendencies acting on them. (Earman \& Roberts 1999: 455)

Cartwright insists that [...] the law attributes to charged bodies the capacity to exert a force on other charged bodies. The exertion of forces, it seems, counts as behavior, whereas the capacity to exert a force does not-so the latter but not the former is the sort of thing we should expect there to be lawlike regularities about. (Earman, Roberts, Smith 2002: 288)
\end{abstract}

Although, a lot counts apparently for $\left(2^{*}\right)$, I will now argue that not $\left(2^{*}\right)$ but $\left(3^{*}\right)$ should be the correct reading of dispositionalism. For that purpose let me consider a practical example Cartwright originally designed as an attempt to show that virtually anything can happen due to a capacity of an object and that, hence, the endeavour to press capacities into the definitorial straight jacket of a single trigger condition and a single manifestation linked by a conditional is not tenable. I will return to this specific threat to interpretations like $\left(2^{*}\right)$ and $\left(3^{*}\right)$ later. Presently, I want to establish that of $\left(2^{*}\right)$ and $\left(3^{*}\right),\left(3^{*}\right)$ is the more accurate reading.

Cartwright states that even the opposite of what we intuitively think should happen when a capacity is active can occur:

There is no one fact of the matter about what occurs when charges interact. With the right kind of structure we can get virtually any motion at all. We can even create environments in which the Coulomb repulsion between two negatively charged particles cause them to move closer together. (Cartwright 1999: 60)

Then follows a description of an experimental setup in which two electrons at distance $r_{1}$ repel each other such that the second one of them moves into a magnetic field (the first is supposed to be held stationary). The initial force between the two electrons is stated as $\mathrm{F}_{\mathrm{C}}=\left(\mathrm{e}_{1} \mathrm{e}_{2}\right) /\left(4 \pi \varepsilon_{0} \mathrm{r}_{1}{ }^{2}\right) .{ }^{16}$ This force causes the second electron to enter the magnetic field with the velocity $v_{1}$. The field is supposed to be set up in strength and direction such that the second electron moves in a circular trajectory back to the first electron. There is an insulation chamber at the side from which it approaches the first electron again. Hence, from this side, the repulsion between the electrons is swallowed by the insulator. All the parameters of the experiment (distances, strength of the magnetic field, etc.) are chosen such that the moving electron comes to a halt at distance $r_{2}$ to the first electron which is smaller than the initial distance $r_{1}$.

Now, with which interpretation, $\left(2^{*}\right)$ or $\left(3^{*}\right)$, can this experiment be best reconciled? ${ }^{17}$ The initial state - two electrons each with unit charge $\mathrm{e}^{-}$in distance $\mathrm{r}_{1}$ - would, according to $\left(2^{*}\right)$, lead to them both having capacity $\mathrm{C}$ which is the capacity to exert a force on each other when circumstances are right. As the experiment has it, circumstances are right such that the full force causes the second electron to accelerate into the magnetic field.

15 I take it that $\mathrm{C}$, the capacity from $(2 *)$, can be identified with "their nature to experience a force of $\mathrm{q} 1 \mathrm{q} 2 / 4 \pi \varepsilon 0 \mathrm{r}^{2}$ " which is the nature to "experience this force if only the right conditions occur".

16 "According to the laws of electromagnetism, the force between the two electrons is a repulsive force equal to $\mathrm{F}=\left(\mathrm{e}_{1} \mathrm{e}_{2}\right) /\left(4 \pi \varepsilon_{0} \mathrm{r}_{1}^{2}\right) . "$ (Cartwright 1999: 60)

${ }^{17}$ One might challenge my line of argument here by saying that focussing on a single experiment cannot be decisive as to whether $(2 *)$ or $\left(3^{*}\right)$ is the correct interpretation. It is quite clear, however, that this experiment is a paradigmatic case for force calculations and additions. Whenever forces are involved we do what we do in this experiment. Hence, this example can well stand for every other experiment. 
What does $\left(3^{*}\right)$ say? Contra $\left(2^{*}\right)$ it says that the force is there in any case-whatever the circumstances. Whether the electron does accelerate into the magnetic field or not is, however, dependent on the circumstances because a force is supposed to be the capacity to accelerate only if the right circumstances occur. But again, the experiment is engineered such that the situation is fortunate and the electron does indeed enter the field with velocity $\mathrm{v}_{1}$ due to the acceleration.

It seems that in order to distinguish a difference between $\left(2^{*}\right)$ and $\left(3^{*}\right)$ we have to make the circumstances less fortunate-but nothing is easier than that. We just have to have a closer look at the scenario to realise that electrons also have mass, that is, we just have to take into consideration that there will also be a gravitational force $F_{G}=-G_{e} m_{e} / r^{2}$ between the two electrons in order to introduce a disturbing factor that makes circumstances less favourable. Now, the story told by $\left(2^{*}\right)$ is that the electrons still have their capacity C. After all, according to $\left(2^{*}\right)$, the connection between charges and capacity $\mathrm{C}$ is supported by a strict law. And yet, $C$ does not (or does so only partially) manifest, i.e., the force $F=\left(e_{1} e_{2}\right) /\left(4 \pi \varepsilon_{0} r_{1}^{2}\right)$ between the two electrons is not (fully) there. The analogous story in terms of $(2 *)$ can be told about Newton's law of gravitation. The gravitational capacity $\mathrm{G}$ is there, however, its manifestation, a gravitational force is not (or is so only partially).

Yet, which force is there? That there must be one is obvious because the second electron is still accelerating into the field. ${ }^{18}$ Well, the answer can be given by school physics: the sum of both forces is responsible for the acceleration. However, turning from schoolbook physics to metaphysics we might ask how on earth it is justified to add forces in order to arrive at the resultant force if those component forces are not there. Coulomb's force (so interpretation $\left(2^{*}\right)$ ) is not there, because masses are around and Newton's force is not there because charges are also around. Why should the addition of both forces be the resultant force if none of the components is actually there? The best we can say about $(2 *)$ is that it leads to a very artificial way of speaking: "Coulomb's [..] force [...] is a hypothetical power hidden away in the actual force." (Cartwright 1992: 48) The worst we can say is that it is misleading because it could make one believe that it is not Coulomb's force $F_{C}=\left(e_{1} e_{2}\right) /\left(4 \pi \varepsilon_{0} r_{1}^{2}\right)$ which is there when masses are also around but that it is a different force (say, $F=1 / 2 e_{1} / 8 \pi r^{7}$ ).

What has $\left(3^{*}\right)$ to say about the whole affair? According to $\left(3^{*}\right)$ both Newton's and Coulomb's force are there. Yet, they are both not (or not fully) manifested because circumstances are not favourable: the two forces are, so to speak, both in each others way. ${ }^{19}$ To see what the resulting force is we add the two while not changing the calculation for each of them. And why should we, for they, the forces, are wholly present.

Earman et al. who, in a quote I have presented above seemed to interpret Cartwright in terms of $\left(2^{*}\right)$, give my reading $\left(3^{*}\right)$ even more credibility when they say in a different quote that

\begin{abstract}
successful physical theories apparently quantify over component forces, and there seems to be no natural way of "paraphrasing away" reference to such forces (as there is for, e.g., references to absolute motion in Newtonian mechanics). Cartwright $(1999,65)$ has suggested that non-total forces are not "occurrent" because they are not measurable. But in the first place, in many cases they are measurable (e.g. a scale measures the impressed gravitational force on an object, not the total force on it - the latter is approximately zero, since the scale itself gives rise to a normal force that keeps the object on it from having a total acceleration downward). And in the second place it is not clear that it follows that something is not occurrent just because it is not measurable." (Earman, Roberts, Smith 2002: 287)
\end{abstract}

Not only is $\left(3^{*}\right)$ in accordance with schoolbook physics and with metaphysics, it also allows for the additions of forces à la $\mathrm{F}=\left(\mathrm{e}_{1} \mathrm{e}_{2}\right) /\left(4 \pi \varepsilon_{0} \mathrm{r}_{1}{ }^{2}\right)-\mathrm{Gm}_{\mathrm{e}} \mathrm{m}_{\mathrm{e}} / \mathrm{r}^{2}$. Moreover, it has also the story

\footnotetext{
${ }^{18}$ I suppose that $\mathrm{F}_{\mathrm{G}}<<\mathrm{F}_{\mathrm{C}}$.

${ }^{19}$ That is, they are 'in each others way' in this case. In other situations they might enforce each other!
} 
about resulting forces right: the resulting force is, just as the component forces, a capacity to accelerate. In case something is in its way (another force) it won't manifest (fully). It is only the total force which will manifest in any case for nothing, by definition, can be in its way.

Let me give a final argument for $(3 *)$. Once one starts questioning what the forces are that interpretation $\left(2^{*}\right)$ defines as 'the manifestation of capacity $\mathrm{C}^{\prime}$, one might be tempted to answer that they are themselves capacities. But then either ontological parsimony would urge us to give up $\left(2^{*}\right)$ for its excessive invention of capacities $\left(\mathrm{C}\right.$ and $\left.\mathrm{F}_{\mathrm{C}}\right)$, or the identification of forces with capacities lets $\left(2^{*}\right)$ collapse into $\left(3^{*}\right)$. For suppose we took the respective part about force capacities from $\left(3^{*}\right)$ and plugged it into $\left(2^{*}\right)$, the result would be:

$\left(2^{*}+3^{*}\right)$ It is a strict law that for any two objects $x$ and $y$ if they have the charges $q$ and $Q$ respectively then $\mathrm{x}$ has the capacity $\mathrm{C}$ which is the capacity to exert the force $\mathrm{F}_{\mathrm{C}}=\mathrm{qQ} /\left(4 \pi \varepsilon_{0} \mathrm{r}^{2}\right)$ on object $\mathrm{y}$ if $\mathrm{x}$ is in distance $\mathrm{r}$ to $\mathrm{y}$, ceteris paribus (and v.v. for $\mathrm{y}$ ) where the force $F_{C}$ is itself the capacity to accelerate $x$ towards $y$ with $a=q Q /\left(4 \pi \varepsilon_{0} r^{2}\right) / m$ if $x$ is in distance $\mathrm{r}$ to $\mathrm{y}$, ceteris paribus (and mutatis mutandis for $\mathrm{y}$ ).

However, since $C^{\prime}$ s antecedent equals $F_{C}$ 's antecedent we can simply cut out $\mathrm{C}$ and stay with $\mathrm{F}_{\mathrm{C}}$ alone:

(i) $\mathrm{C}(\mathrm{x}) \quad \leftrightarrow$ if $\mathrm{x}$ is in distance $\mathrm{r}$ to $\mathrm{y}$ then $\mathrm{F}_{\mathrm{C}}(\mathrm{x})$, ceteris paribus. [from $\left(2^{*}\right)$ ]

(ii) $\mathrm{F}_{\mathrm{C}}(\mathrm{x}) \quad \leftrightarrow$ if $\mathrm{x}$ is in distance $\mathrm{r}$ to $\mathrm{y}$ then $\mathrm{x}$ accelerates towards $\mathrm{y}$ with $\mathrm{a}=\mathrm{qQ} /\left(4 \pi \varepsilon_{0} \mathrm{r}^{2}\right) / \mathrm{m}$, ceteris paribus. [assumption that forces are capacities]

(iii) $\mathrm{C}(\mathrm{x}) \quad \leftrightarrow$ if $\mathrm{x}$ is in distance $\mathrm{r}$ to $\mathrm{y}$ then (if $\mathrm{x}$ is in distance $\mathrm{r}$ to $\mathrm{y}$ then $\mathrm{x}$ accelerates towards y with $\mathrm{a}=\mathrm{qQ} /\left(4 \pi \varepsilon_{0} \mathrm{r}^{2}\right) / \mathrm{m}$, ceteris paribus $)$, ceteris paribus. [taking (i) and (ii) together]

(iv) $\mathrm{C}(\mathrm{x}) \quad \leftrightarrow$ (if $\mathrm{x}$ is in distance $\mathrm{r}$ to $\mathrm{y}$ then $\mathrm{x}$ accelerates towards $\mathrm{y}$ with $\mathrm{a}=\mathrm{qQ} /\left(4 \pi \varepsilon_{0} \mathrm{r}^{2}\right) / \mathrm{m}$, ceteris paribus $)$, ceteris paribus. [propositional logic: $\mathrm{p} \rightarrow(\mathrm{p} \rightarrow \mathrm{q}) \leftrightarrow$ $(\mathrm{p} \rightarrow \mathrm{q})]$

(v) $\mathrm{C}(\mathrm{x}) \quad \leftrightarrow$ if $\mathrm{x}$ is in distance $\mathrm{r}$ to $\mathrm{y}$ then $\mathrm{x}$ accelerates towards $\mathrm{y}$ with $\mathrm{a}=\mathrm{qQ} /\left(4 \pi \varepsilon_{0} \mathrm{r}^{2}\right) / \mathrm{m}$, ceteris paribus. [what can be put into two ceteris paribus clauses can be put into one]

(vi) $\mathrm{C}(\mathrm{x}) \quad \leftrightarrow \mathrm{F}_{\mathrm{C}}(\mathrm{x})[$ by (ii)]

Hence,

(vii) If forces are capacities then $(2 *) \leftrightarrow\left(3^{*}\right)$

I have already quoted a claim from Cartwright which is in agreement with interpretation $\left(3^{*}\right)$. To further foster my stance that $\left(3^{*}\right)$ is right, let me repeat this claim: "It is in the nature of a force to produce an acceleration of the requisite size. That means that ceteris paribus, it will produce that acceleration." (Cartwright 1999: 28; my emphasis)

Finally, I have to face a challenge against my whole attempt to give an analysis of the dispositions of dispositionalism. Cartwright claims:

What is important about capacities is their open-endedness: what we know about them suggests strategies rather than underwriting conclusions [...]. To see the open-endedness it is useful to understand how capacities differ from dispositions. Dispositional terms, as they are usually understood, are tied one-to-one to law-like regularities. But capacities, as I use the term, are not restricted to any single kind of manifestation. Objects with a given capacity can behave very differently in different circumstances. (Cartwright 1999:59)

[Capacities] give rise to highly varied behaviours. [...] The point I want to stress is that capacities are not to be identified with any particular manifestation. (Cartwright 1999:64)

There is no one fact of the matter about what occurs when charges interact. With the right kind of structure we can get virtually any motion at all. We can even create environments in which the Coulomb repulsion between two negatively charged particles cause them to move 
closer together. (Cartwright 1999: 60)

So both my attempts, even $\left(3^{*}\right)$ - are in vain because both try to identify a "single kind of manifestation"? ${ }^{20}$ Have I misunderstood dispositionalism completely because I am addicted to a die hard Humeanism which demands analyses for dispositions in kosher Humean terms: observable categorical properties linked by a (counterfactual) conditional? What dispositionalism is about, so dispositionalists might claim, is, after all, that a characterisation of capacities is not needed, semantic analysis not in demand. Dispositionalists accept capacities as basic and non definable entities. So all my efforts are in vain. Or are they?

My first, weak, argument is an appeal to what other dispositionalists say. Compare for example to Stephen Mumford:

The stimulus and manifestation conditions [...] are quite tightly defined and follow from the disposition ascription by conceptual necessity. (Mumford 1998: 92; my emphasis)

A disposition ascription thus invokes the following 'conditional conditional': [ $\left.\mathrm{Df}_{\mathrm{i}}\right]$ if $\mathrm{Ci}$, then (if $\mathrm{F}(\mathrm{x})$, then $\mathrm{G}(\mathrm{x})$ ). Where $\mathrm{Ci}$ represents the ideal conditions, $\mathrm{F}$ and $\mathrm{G}$ represent stimulus and manifestation respectively, and both conditionals have subjunctive force. (Mumford 1998: 88)

That Mumford also urges

that the concept of a disposition is something that goes beyond complexes of observable events and, thus, that the conditional analysis fails to analyse or reduce disposition concepts. (Mumford 1998: 37)

and that

it will be admitted that there is a connection between dispositions and conditionals, as the reductionists urge, but it will be shown that the relationship is not one of equivalence, contrary to their claims. (Mumford 1998: 37)

does not matter to me. I do not claim to have fully analysed the dispositional terms in giving interpretation $\left(3^{*}\right)$. My sole purpose is to show that the ceteris paribus clause reappears for dispositionalists even if we do not intend to reduce the dispositional predicate. Mumford happily concedes that theorising about dispositions includes theorising about proviso clauses and dedicates three subchapters 4.7 - 4.9 (Mumford 1998: 81-91) of his book Dispositions to the analysis of ceteris paribus clauses in dispositional predicates.

Peter Lipton can serve as a second example of a dispositionalist who accepts the reoccurrence of the ceteris paribus clause. He, contra Cartwright and Mumford, even accepts the full conditional analysis of dispositional predicates as will be shown later.

In the meanwhile let me give a second, stronger and decisive reason against Cartwright's creed that "capacities are not to be identified with any particular manifestation". This second reason comes from the standard toolbox of analytic philosophy: 'No entity without identity!'. Asking for the identification criteria of a certain disposition we are forced to accept at least that there is, for each disposition, a unique set of if-then sentences linking trigger conditions to manifestations. No such set, no such entity.

The illusion of a multitude of manifestations occurs when the scope of the disposition's effect is taken too widely. Fragility, one could claim, has a multitude of manifestations: to cause a glass to break and Denis to fetch the vacuum cleaner; to cause a vase to shatter and Barbara to scream; etc. And yet, what Barbara and Denis do when fragile things break does not really belong to the manifestation of fragility. Moreover, if I warn someone that the things in the box they carry are fragile they do not reply that that does not

\footnotetext{
${ }^{20}$ Note that I have used the term 'disposition' deviating from Cartwright's special use in her quote. For me 'disposition' has been an umbrella term for capacities, powers, tendencies, etc. and I will keep this interpretation. In Cartwright's terms, however, I have confused capacities with dispositions when giving interpretations $\left(2^{*}\right)$ and $(3 *)$.
} 
matter because there are so many different things fragile things can do and that they might even behave quite differently from what we would think they do (bounce back, for example). Returning to forces (and other scientific dispositions) I finally want to point out that for other important arguments Cartwright lists in her books pro dispositionalism (which are not related to the ceteris paribus issue, namely, the argument from material abstraction or the argument from transportability she needs circumscribed triggers and manifestations. The argument from material abstraction (in Cartwright's Nature's Capacities and their Measurement) convincingly says that in order to be able to successfully describe an actual experimental setup or the workings of a certain apparatus (a laser for example) we need to consider an abundance of factors which we might have omitted when initially planning the experiment roughly on paper: ${ }^{21}$

"The omitted factors must be added in again. But where do these omitted factors come from? I have already described the answer I believe in: given a theory, the factors come from a list." (Cartwright 1989: 207) ${ }^{22}$

Clearly, Cartwright's lists are in most cases an abstract idea. Only rarely are there actual lists stored on the hard-drives of scientists. ${ }^{23}$ And yet we can ask how we have to imagine, in principle, the entries in those lists and how to read them. If we stopped with Cartwright's claims that

\section{Capacities $[\ldots]$ are not restricted to any single kind of manifestation. Objects with a given} capacity can behave very differently in different circumstances. (Cartwright 1999:59)

[Capacities] give rise to highly varied behaviours. [...] The point I want to stress is that capacities are not to be identified with any particular manifestation. (Cartwright 1999:64)

we could not possibly have any good criteria for when to include a factor with its capacity in those lists nor would we have guidelines as to how to bring them into a useful order. To state it in the extreme: if we only said that charges have a capacity which "gives rise to highly varied behaviours" we would not know how to account for charge as a factor in a given situation. Only by mentioning at least one typical trigger and at least one typical manifestation can we include charges as factors on our lists.

A further argument of Cartwright's says that if capacities of certain structures are stably linked to these structures then we can safely suppose that these structures carry the capacity with them from situation to situation. This reliable link enables us to predict or at least guess how the structure will behave in different situations.

The point is that we want to learn something from an experiment that is transportable to entirely new situations where quite different circumstances obtain. We do that [...] by learning the nature of the pieces from which the new situations are built." (Cartwright 1992: 56)

However, for the stable link to be of any use there must also be stable links from capacities to their triggers and effects. Without a regular (maybe even lawful or analytic) link from a disposition to a manifestation transportation, explanation and prediction would not be possible.

Capacities, so I want to end this paragraph, have at least a set of trigger-manifestation

\footnotetext{
${ }^{21}$ I identify factor with capacity.

${ }^{22}$ The goal of Cartwright's argument from material abstraction differs from what I want to prove here. Her aim is to show that those lists will never be comprehensive enough to predict the phenomena of actual situations absolute correctly. She claims that there will always be unknown or forgotten factors such that we have no chance for $100 \%$ accuracy.

${ }^{23}$ She mentions the case of Hamiltonians in physics textbooks which are indeed assembled in actual lists. The description of a concrete quantum mechanical system is "essentially [...] built up by pieces" (Cartwright 1989: 205) Those pieces are included in one's repertoire of Hamiltonians: "At the start in quantum mechanics one learns a series of model Hamiltonians." (Cartwright 1989: 205)
} 
pairs, even if they are not related to a single trigger-manifestation duo. ${ }^{24}$

\section{JUST HOW BAD IS THE REOCCURRENCE OF THE CETERIS PARIBUS CLAUSE?}

Before I point out a second set of difficulties dispositionalism must solve if it is to be a viable strategy to avoid the problems of ceteris paribus laws let me ask how bad the reoccurrence of the ceteris paribus clause in $\left(3^{*}\right)$ is. I have already formulated the threat: the disposition is a veiling strategy, hiding the ceteris paribus clause under the burka of the capacity term.

It is well known that this ceteris paribus clause which is intrinsic to the dispositional predicate has already appeared as a stumbling block in the history of philosophy of science / logical empiricism. It caused the same kind of trouble as the ceteris paribus clause in laws. Whilst, however, the ceteris paribus law debate has only recently moved into the focus of philosophy of science - cf. Erkenntnis (3) 2002 - people have struggled with the analysis of dispositional predicates from the heydays of logical empiricism (cf. Carnap 1936/37). The most recent papers come from Martin, Lewis, Bird, Mumford, Molnar and Malzkorn, to name but a few. ${ }^{25}$

Just to give the flavour of the recent debate: in "Dispositions and Conditionals" (Martin 1994), C. B. Martin has convincingly shown that the bare conditional analysis of dispositions, like

$\mathrm{x}$ has the disposition $\mathrm{D} \leftrightarrow$ if $\mathrm{x}$ were exposed to the test $\mathrm{T}$, $\mathrm{x}$ would show the reaction $\mathrm{R}$

is not adequate. The counterfactual conditional is neither sufficient nor necessary for an object to be disposed. Martin's example is a live ${ }^{26}$ wire (live being the disposition in question) to which a machine - an electro-fink - is connected. This machine is built in such a way that it stops the power supply immediately if the wire is touched by a conductor. The conditional analysis of " $\mathrm{x}$ is live" taken to be "if $\mathrm{x}$ were touched by a conductor, then electric current would flow from $\mathrm{x}$ to the conductor" is false, since the wire is live ex hypothesi but the conditional is not true due to the fink. Hence, the conditional is not a necessary condition for the disposition. An analogous story can be told about a non-live wire and a reverse-electrofink such that the conditional is not sufficient.

One could reply that the peculiar intervention of the fink does not belong to what normally happens. This suggests that we upgrade the analysans: 'Dx $\leftrightarrow$ Under normal conditions, if ...' seems to be more appropriate.

But now we are committed to say more precisely what we mean by "normal conditions" or, to put it another way, to specify which cases should be excluded (which is what Martin attempts to do). In this latter class all finks must be included, i.e., more precisely, all conceivable kinds of finks. Such a list would clearly be infinite and thus not listable for human beings. An extensional definition being implausible, we have instead to think about a descriptive criterion common to all finks.

To this purpose, Martin suggests introducing a "principle of inclusion":

The principle of inclusion in the set is similarity of the effects produced by each of the member events. Similarity in which respect? The answer is, that each of these events brings it about that it is not the case that the wire is live at a certain time (Martin 1994: 6).

But if we define normal conditions as the complement of the class defined by Martin's principle of inclusion, we end up in a circle:

$\mathrm{x}$ has the disposition $\mathrm{D} \leftrightarrow$ the following holds under conditions where there is no event which brings it about that it is not the case that $\mathrm{x}$ has the disposition: if $\mathrm{x}$ were exposed to

\footnotetext{
${ }^{24}$ I have the intuition, though, that we could even press for a single pair in case of scientific capacities.

${ }^{25}$ Cf. (Martin 1994), (Lewis 1997), (Bird 1998), (Molnar 1999), (Malzkorn 2000), (Mumford 2001).

${ }^{26}$ Other examples may be found easily if someone doubts that being live is a disposition.
} 
the test $\mathrm{T}, \mathrm{x}$ would show the reaction $\mathrm{R}$

We are indeed back to the same kind of problems I have mentioned in $\S 2$ for laws.

Possible solutions in the case of dispositions have been offered. Here I can only hint at an account which has been offered by Alexander Bird in the dispositions debate (Bird 1998) and then been taken up by Peter Lipton (Lipton 1999) for the dispositionalism vs. ceteris paribus laws debate.

Bird suggests to fix the reference of the unknown or indefinable ideal or normal conditions via a Putnamian reference to archetypal situations: "[...] we are thinking of cases like this one" (1998: 234). In the past we have already positively tested objects of the same kind as the object now under examination. Situations, circumstances like in those successful test cases form the class $\mathrm{C}$ of ideal conditions.

We see one hundred identical glasses break easily when struck. [...] we say that they are disposed to break when struck. Here $\mathrm{C}$ will be these hundred glasses and their breaking when struck. (Bird 1998: 234)

In the last passage of his article Bird explicitly refers to Putnam's claims about the way the extension of natural kind terms is fixed: by referring to paradigm examples.

Now, while Bird has the ideal or normal circumstances treated in a Putnamian way Lipton sees the disposition term as a whole subject to externalist semantics: in a paragraph Hume's Revenge of his All Else Being Equal article Peter Lipton accepts a hard core Humean challenge to dispositionalism. Instead of adopting a dispositionalism à la Mumford-which accepts a link between dispositions and conditionals but denies that dispositions are analysable in terms of conditionals - and simply denying the following argument Lipton accepts its challenge:

\begin{abstract}
What does it mean to say that something is 'fragile'? The meaning must it seems be given through a corresponding conditional, in this case, roughly speaking, 'if it were to drop, it would break'. Our semantic grip on the dispositional term will, on this natural view, only be as good as our semantic grip on the corresponding conditional. In the case of cp laws, however, this is no good at all, precisely because we cannot specify under what conditions the disposition will manifest itself. In short, the Humean's revenge is to claim, plausibly enough, that the detour through the disposition has made absolutely no difference so far as the problem of content is concerned. (Lipton 1999: 167)
\end{abstract}

For my purposes it does not matter that Lipton does not adopt a Mumfordian dispositionalism and denies that "meaning must [...] be given through a corresponding conditional" for if he can find a solution for the ceteris paribus clause for his dispositionalism he will, a fortiori, have found one for a weaker one.

Lipton proposes externalist semantics as solution. The meaning of dispositional terms, he claims, can partially be fixed by reference to paradigm cases:

\begin{abstract}
Here as elsewhere in the philosophy of language, a situation where there is a combination of semantic determinacy and lack of articulate knowledge about the extension or referent provides a strong argument for some form of semantic externalism. The idea, in roughest outline, would be that dispositional terms are natural kind terms that get their content by a combination of exemplary cases, theoretical knowledge and actual kind structure of the world, not simply in virtue of what is in user's heads. (Lipton 1999: 167)
\end{abstract}

Many questions are still to be answered. For example, why can't the Humean claim that the same solution is available to the antecedents of laws incorporating ceteris paribus clauses? Why not deal with the ceteris paribus clause at the law level in that way? Lipton has some answers to give (cf. Lipton 1999: 168) which I cannot discuss here but he concedes that a fully-fledged analysis is still to be formulated. ${ }^{27}$

\footnotetext{
${ }^{27}$ Which can be seen from remarks like "However the semantic details of this externalist response are filled in, .." (Lipton 1999: 167)
} 
Yet, even if Lipton, Bird etc. find a solution for this type of ceteris paribus clause ${ }^{28}$ there is another one lurking in the background which can't be captured by these accounts. But before I turn to this further blow to dispositionalism let me focus briefly on an interesting because radical remark of Cartwright's: "For all we know", she writes, "most of what occurs in nature occurs by hap, subject to no law at all." (Cartwright 1999:1) Does that mean that most events are not even guarded by the actions of capacities? When she uses the word 'laws' Cartwright frequently oscillates between referring to regularities on the one hand and to ascriptions of capacities on the other hand. This makes it difficult to decide how radical her claim is meant to be. If we suppose she means "subject to no capacity at all" then her statement would, indeed, be a claim to the effect that there is usually, in most cases, anarchy instead of law-like behaviour. Other quotes seem to support this radically anarchical stance:

\begin{abstract}
For any body in any situation, if nothing intervenes, its acceleration will equal the force exerted on it divided by its mass. But what can interfere in the production of motion other than another force? Surely there is no problem. The acceleration will always be equal to the total force divided by the mass. That is just what I question. (Cartwright 1999: 26; my emphasis)
\end{abstract}

Moreover, philosophers like Earman and Roberts seem to read her in this very strong way: "Cartwright concludes, however, that there are no strict lawlike regularities in nature at all, not even ones that can be only stated in a richer vocabulary that mentions capacities." (Earman and Roberts 1999: 475, Fn. 27)

\title{
8 Ceteris paribus Clauses Shooting up like Mushrooms
}

Having so far focussed on the (alleged) fundamental laws of physics, we have overlooked a widespread phenomenon which, again, causes trouble in terms of ceteris paribus clauses. To hint at the problem consider the following remark: "For dispositions [there is] [...] a tripartite distinction: displaying, present-but-not-displaying, or absent." (Lipton 1999: 163)

Additionally, recall the remark I made earlier when I turned (3) into (3*). There I said that, in principle, there is another logical possibility to accommodate the need for a ceteris paribus caveat. We could claim, I said, that the antecedent of the law (not the capacity) has to bear the ceteris paribus clause to the effect that not in any circumstances a charged object $\mathrm{x}$ would have Coulomb's force capacity $\mathrm{F}_{\mathrm{C}}$ : it is a law (not a strict law!) that for any two objects $\mathrm{x}$ and $\mathrm{y}$ if they have charge $\mathrm{q}$ and $\mathrm{Q}$ respectively then $\mathrm{x}$ has, ceteris paribus, Coulomb's force capacity $\mathrm{F}_{\mathrm{C}}$. Now put Lipton's and my claim together and we arrive at the well known phenomenon that a disposition cannot only fail to manifest itself (while still being there) but also that it can be lost and, hence, absent. This possibility did not spring to mind before because fundamental laws of physics claim strict relations between certain entities - charges, for example - and capacities (here Coulomb's capacity). ${ }^{29}$

But the point is that at least the dispositions of sciences further down the hierarchy (chemistry, biology, psychology, etc.) can not only fail to manifest, they can also fail to be present. ${ }^{30}$ Like rubber can cease to be elastic because the material gets brittle when aged

\footnotetext{
${ }^{28}$ Bird has already been criticised by Gunderson (Gunderson 2000) (with a reply by Bird (Bird 2000)) and by Sungho Choi (2003).

${ }^{29}$ In fact, the insulator in the described experiment above shows that Coulomb's law can have an exception of the kind to be analysed in this paragraph, that is, if there is an insulator the force is not even there (as opposed to being counteracted against). It should be mentioned, however, that Coulomb's law is not as fundamental as I have pretended it to be. Actually, it can be derived from Maxwell's equations which do not have an exception in the insulator case.

${ }^{30}$ The ultimate reason is that - with the possible exception of the dispositions of fundamental physics - all dispositions have a basis. If the basis is lost so is the disposition. It is an interesting question whether the
} 
scientific dispositions can be lost because their underlying basis breaks or alters. Haemoglobin cells might be damaged and not be able to bind $\mathrm{O}_{2}$ anymore, birds might lose their ability to fly because their wings are broken, peaceful people might turn irascible because of accidental brain damages, etc.

So when we state 'haemoglobin binds $\mathrm{O}_{2}$, ceteris paribus' we might mean two things, that, normally, in most cases, haemoglobin has the capacity to bind $\mathrm{O}_{2}$ and furthermore that, even if haemoglobin cells have the capacity, they might still not bind $\mathrm{O}_{2}$ because, say, too much $\mathrm{CO}$ is around. Hence, we get a double proviso for laws about dispositions that can be lost:

$\left(3^{* *}\right)$ It is a law that for any object $\mathrm{x}$ if it has feature $\mathrm{F}$ it has, ceteris paribus, the capacity

$\mathrm{C}$, which is the capacity to do $\mathrm{M}$ if trigger conditions $\mathrm{T}$ are met, ceteris paribus.

The first ceteris paribus clause stands for the presence or absence of the disposition, the second for its manifestation or lack of manifestation. The double ceteris paribus clause is an unattractive but necessary element if the capacities concerned can be lost. Focussing only on the law's ceteris paribus proviso, the one of interest here in $\S 8$, I abbreviate $(3 * *)$ to:

$(3 * * *)$ It is a law that for any object $\mathrm{x}$ if it has feature $\mathrm{F}$ it has, ceteris paribus, the capacity

C.

Now how do the dispositionalists deal with this ceteris paribus clause?

It is only fair to mention that dispositionalists are not completely unaware of the phenomenon. However, they do not link the fact that a disposition can be lost to the ceteris paribus issue.

First consider Lipton:

I have already suggested that what counts is the stability of the disposition. (Lipton 1999: 165 ; my emphasis)

To say that glass breaks when dropped, $\mathrm{cp}$, is to say that glass is fragile and that this feature is not readily lost. To say that iron filings will arrange themselves around a bar magnet in a specified pattern, cp, is to say that magnets exert a certain sort of force on iron filings, a disposition magnets do not lose while remaining magnets. (Lipton 1999: 162; my emphasis)

Note, however, that while Lipton's statements correctly hint at the fact that there are stable and unstable dispositions it is nonetheless problematic. Saying that magnets exert a certain sort of force on iron filings, a disposition magnets do not lose while remaining magnets is analogous to saying that fragile things break easily when dropped, a disposition fragile things do not lose while remaining fragile things. Being magnetic is already the disposition contra being glass in Lipton's first example. Instead of magnetism, Lipton should have, e.g., chosen being an electron: electrons exert a certain sort of force on other charged particles, $a$ disposition electrons do not lose while remaining electrons. ${ }^{31}$ Anyway, there is no allusion to the double ceteris paribus clause that is needed.

Consider furthermore Cartwright on enduring capacities; capacities that cannot be lost:

The laws of electromagnetic repulsion and attraction, like the law of gravity, and a host of other laws as well, are laws about enduring tendencies or capacities. (Cartwright 1989: 1; my emphasis)

And compare them to those which are non-enduring capacities:

The property that carries the capacity interacts with some specific feature of the new

\footnotetext{
dispositions of fundamental physics, if they are baseless, can be lost. Maybe the strong claims I quoted from Cartwright at the end of the last paragraph point in this direction.

31 Whether glass can lose its disposition to be fragile is questionable. Maybe we can safely say that the amorphous structure of glass can be arranged and modified such that it becomes bullet-proof and is, consequently, not fragile anymore.
} 
situation, and the nature of the capacity is changed. It no longer has the power that it used to. (Cartwright 1989: 163) ${ }^{32}$

The acid and the base neutralize each other. Each destroys the chemical power of the other, and the peculiar chemical effects of both are eliminated. This is not like the stationary particle, held in place by the tug of forces in opposite directions. When an acid and a base mix, their effects do not combine: neither can operate to produce any effects at all. (Cartwright 1989:163) (33 $^{33}$

The acid and the base simply lose their capacity where the forces of the particle are still there although they do not manifest. ${ }^{34}$ And yet, while the possibility of a lost capacity has been acknowledged the unavoidable consequence that laws which link kinds of objects to those unstable capacities are ceteris paribus laws has been withheld. ${ }^{35}$

However, Lipton might have seen the danger of this result:

I have already suggested that what counts is the stability of the disposition. It also suggests that we might replace the law/accident dichotomy by a continuum, since stability is a matter of degree. (Lipton 1999: 165; my emphasis)

Note that then the degree to which something is a law statement (rather than an accidental generalisation) varies with the degree in which it has to have ceteris paribus clauses. Therefore, for those statements which are lawlike to a very high but not the highest degree Lipton's statement that "we don't know when all things are equal, but the whole point of the dispositional view is in a sense that we do not need to know, since the disposition is present regardless." (Lipton 1999: 166) is false.

Not to forget that even if his strategy (introduced in $\S 7$ to rescue dispositionalism from the arguments in §6) to apply semantic externalism to the problem for ceteris paribus clauses inside dispositional predicates will turn out to be successful, it cannot be applied to the laws which link properties to instable capacities.

\footnotetext{
32 Ontologically, this is a confusing statement because the term 'nature' is used in a deviating meaning from the rest of Cartwright's quotes (and books). In this statement it should not be read in the usual way as synonymous with disposition, power, capacity but should be read rather as essence or core. Otherwise the capacity which is carried by the property is said to posses a power or capacity itself. After these changes the quote reads: "The property that carries the capacity interacts with some specific feature of the new situation, and the essence of the capacity is changed." Furthermore, it has to be underlined that the 'It' of the sentence "It no longer has the power that it used to" must refer to the property of the first sentence not to the capacity - so as to avoid (again) the undesirable talk about the capacities or powers of capacities. Finally, we might ask whether a property can interact with situations and even change thereby or whether we should rather talk about objects that interact and lose or change properties and thereby capacities. As a consequence, I suggest the following rephrasing: "The object that has a capacity qua having a certain property or structure interacts with some specific feature of the new situation and changes its property or structure. Thereby, it loses its initial capacity while (perhaps) acquiring a new one. It (the object) has no longer the power that it used to".

${ }^{33}$ Note that Cartwright confesses here that there are certain effects in the case of a stationary particle, held in place by a tug of forces in opposite directions, say a gravitational and an electromagnetic force. First of all, this remark underlines once more the advantage of $\left(3^{*}\right)$ over $(2 *)$. Additionally, it seems to be at odds with her later claim that "Coulomb's is not the force that actually occurs; rather, it is a hypothetical power hidden away in the actual force." (Cartwright 1992: 48; my emphasis) If the term 'hypothetical' has its usual connotation of 'not being there in reality, just by human stipulation' then both 'hypothetical' and 'hidden away' seem to contradict 'having certain effects' and 'not being neutralised' (like the acid and the base).

${ }^{34}$ In footnote 8 I pointed out that on top of Lipton's tripartite distinction for dispositions-displaying, presentbut-not-displaying, or absent—we must, for some dispositions, have a fourth state: not-displaying-but-pressingto-display.

${ }^{35}$ While focussing on taxonomic laws Alice Drewery has shown that dispositionalism is not applicable there either: "We can and do generalise about categorical properties of individuals. For example, the law that all atoms have the same number of protons and electrons does not obviously seem to involve a disposition. [...] $\mathrm{Cp}$, horses are vegetarians. $\mathrm{Cp}$, all rubber bands are elastic. Cp, all mammals give birth to live young." (Drewery 2001: 726) She has also, similar to my claim above, pointed out that: "Not all cp-clauses describe a failure to manifest behaviour: some describe a lack of a disposition." (Drewery 2001: 727)
} 
To end the paragraph and the paper, let me suggest a mad strategy. Turn ( $3 * * *)$ into:

It is a strict law that Fs have the capacity $\mathrm{C}^{+}$to have the capacity $\mathrm{C}$.

\section{CONCLUSION}

I hope to have shown that dispositionalism cannot claim to have solved or avoided the problems ceteris paribus clauses in laws create; for not only does the ceteris paribus clause reoccur inside the dispositions, but further, there are laws-laws about non-fundamental entities with instable dispositions - which bear a ceteris paribus clause that cannot be hidden in a disposition.

\section{ACKNOWLEDGEMENTS}

Thanks is due to Jeremy Butterfield, Nancy Cartwright, Max Kistler, James Logue, Thomas Müller, Stephen Mumford, Barbara Stafford, and Rainer Stuhlmann-Laeisz for helpful comments on earlier versions and to the participants at the conference Dispositions et pouvoirs causaux in Paris, September 2002, for their supportive questions and critique.

\section{LITERATURE}

Bartels, A. 2000. The Idea which we call Power. Naturgesetze und Dispositionen. Philosophia Naturalis 37 (2000) 255-268.

Bird, A. 1998. Dispositions and Antidotes. Philosophical Quarterly 48 (1998) 227-234.

Bird, A. 2000. Further Antidotes: A replay to Gundersen Philosophical Quarterly 50 (2000) 229-233.

Carnap, R. 1936. Testability and Meaning I. Philosophy of Science 3 (1936) 419-471.

Carnap, R. 1937. Testability and Meaning II. Philosophy of Science 4 (1937) 1-40.

Cartwright, N. 1989. Nature's Capacities and their Measurement. Oxford, OUP 1989.

Cartwright, N. 1992. Aristotelian Natures and the Modern Experimental Method. In Inference, Explanation, and other Frustrations: Essays in the Philosophy of Science. John Earman (ed.). Berkeley, Los Angeles, Oxford 1992: 44-71. [Also in (Cartwright 1999) as chapter 4.]

Cartwright, N. 1995. Precis of Nature's Capacities and Their Measurement (in Book Symposia). Philosophy and Phenomenological Research. 55(1) (1995) 153-156.

Cartwright, N. 1999. The Dappled World. A Study of the Boundaries of Science. Cambridge, CUP 1999.

Cartwright, N. 2002. In Favor of Laws that Are Not Ceteris paribus After All. Erkenntnis 57(3) (2002) 425-439.

Choi, S. 2003. Improving Bird's Antidotes. Australasian Journal of Philosophy. 81(4) (2003) 573-580.

Drewery, A. 2001. Dispositions and Ceteris Paribus Laws. British Journal for the Philosophy of Science. 52 (2001) 723-733.

Earman J., Glymour, C., Mitchell, S. D. (eds.) 2002. Erkenntnis 57(3) (2002). Special Volume on Ceteris paribus Laws.

Earman, J., Roberts, J. 1999. Ceteris paribus, there is no Problem of Provisos. Synthese 118 
(1999) 439-478.

Earman, Roberts, and Smith. 2002. 'Ceteris paribus' Lost. In Earman J., Glymour, C., Mitchell, S. D. (eds.) 2002: 281-301.

Gunderson, L. B. 2000. Bird on Dispositions and Antidotes. Philosophical Quarterly 50 (2000) 227-229.

Harré, R. 1993. Laws of Nature. London: Duckworth 1993.

Hempel, C.G. 1988. Provisos: A Problem Concerning the Inferential Function of Scientific Theories. In A. Grunbaum and W. Salmon (eds.) The Limitations of Deduction. Berkeley: University of California Press 1988. [Also in Erkenntnis 28 (1988) 147-64.

Hüttemann, A. 1998. Laws and Dispositions. Philosophy of Science 65 (1998) 121-135.

Kistler, M. 2003. Laws of Nature, Exceptions and Tropes. Philosophia Scientiae 7 (2) (2003): 189-219.

Lewis, D. 1997. Finkish Dispositions. Philosophical Quarterly 47 (1997) 143-158.

Lipton, P. 1999. All else being equal. Philosophy 74 (1999) 155-68.

Malzkorn, W. 2000. Realism, Functionalism and the conditional Analysis of Dispositions. Philosophical Quarterly 50(201) (2000), 452 - 469.

Martin, C.B. 1994. Dispositions and Conditionals. The Philosophical Quarterly 44 (1994) 1-8.

Molnar, G. 1999. Are Dispositions Reducible? Philosophical Quarterly 49 (1999) 1-17.

Mumford, S. 1998. Dispositions Oxford: 1998.

Mumford, S. 2001. Realism and the Conditional Analysis of Dispositions: Reply to Malzkorn. Philosophical Quarterly 51 (2001) 375-378. 